\title{
Influence of Effective Pressure on Percolation Rate of Coal
}

\author{
Fukun Xiao $\mathbb{D}^{1,2}$ Wenhai Xu, ${ }^{3,4}$ Renhe $\mathrm{Li}^{2}{ }^{2}$ Fengrui Zhang, ${ }^{2}$ Lei Xu $\left(\mathbb{C}^{2}{ }^{2}\right.$ Le Xing, \\ and Zhiyuan Hou $\mathbb{B D}^{2}$ \\ ${ }^{1}$ Heilongjiang Ground Pressure \& Gas Control in Deep Mining Key Laboratory, \\ Heilongjiang University of Science and Technology, Harbin, Heilongjiang 150022, China \\ ${ }^{2}$ College of Mining Engineering of Hust, Heilongjiang University of Science and Technology, Harbin, Heilongjiang 150022, China \\ ${ }^{3}$ School of Safety Engineering, Heilongjiang University of Science \& Technology, Harbin, Heilongjiang 150022, China \\ ${ }^{4}$ Longhu Coal Mine of Qitaihe Mining Co.,Ltd of Heilongjiang Longmei Group, Qitaihe, Heilongjiang 154622, China
}

Correspondence should be addressed to Fukun Xiao; xiaofukun@hotmail.com

Received 21 February 2021; Accepted 6 May 2021; Published 24 May 2021

Academic Editor: Xianjie Hao

Copyright (c) 2021 Fukun Xiao et al. This is an open access article distributed under the Creative Commons Attribution License, which permits unrestricted use, distribution, and reproduction in any medium, provided the original work is properly cited.

To study the role of the effective pressure on the percolation rate of coal, the effect of gas pressure, gas adsorption, and temperature on coal is taken into consideration comprehensively. Starting from the research direction of effective pressure and porosity, the coal body percolation rate and effective pressure equations considering the influence of temperature and gas pressure are established. The experiments on the percolation characteristics of raw coal are implemented under different effective pressure by using the independently developed thermos-solid-gas linking triaxial servosystem. The theoretical equation of the effective pressure and percolation rate of coal is calculated with the finite element software COMSOL, and the results obtained from the theoretical equation agree well with the experimental results. The results show that the percolation rate of coal gradually decreases with the growth of the effective pressure when the gas pressure and temperature are kept unchanged. Therefore, the results of the research are of certain reference value for the effective prevention of gas disaster.

\section{Introduction}

Understanding the alteration of the percolation rate of coal is the key point for the regulation and control of the gas dynamic disaster. When mining the coal seam, there is effective pressure in the engineering environment, which leads to the compression deformation of the local coal body. Consequently, the porosity is decreased, and the gas percolation rate is hindered; on the contrary, due to the pressure relief effect, a part of the coal body experiences stretching deformation, forming new cracks in the coal layer, thereby increasing the percolation rate of coal. The variation of coal effective pressure may induce changes in the fissured coal field, or even porosity, thereby triggering the dynamic evolution of the percolation rate eventually. In the evolution process, the changes of the effective force have a significant impact on the dynamic evolution of the percolation rate. Therefore, it is indispensable to search the law of the changes for coal percolation rate and the effective pressure.
Many achievements have been made in the study of the effect of effective pressure on the coal percolation rate. Jiang et al. [1] studied the influence of effective pressure on the percolation rate mechanism through theoretical and experimental research, respectively. The influence of the effective pressure was analyzed, and its exponential function was obtained as the mathematical expression for cubic polynomial through theoretical and experimental analyses of the effective pressure and the percolation rate. Tang et al. $[2,3]$ used the self-developed experimental equipment for gas seepage adsorption experiments in which the effective pressure was loaded and unloaded, thereby obtaining the law of gas seepage and adsorption under complex effective pressure conditions. He et al. [4-6] studied the effect of different effective pressures and temperatures on the porosity and percolation rate of sandstone. The above scholars focused on the relationship between effective pressure and percolation rate, but the research methods were still insufficient. 
The effect mechanism of the porosity and percolation rate of sandstone was studied through experiments by many scholars. Zeng et al. [7, 8] obtained the relationship between effective pressure and the percolation rate of low percolation rate sandstone based on a large number of experiments in the laboratory. Dai et al. [9] found out that the influence of effective pressure on the porosity is smaller, but larger on the percolation rate through the test. Kang et al. [10,11] obtained the law of change for pore structure parameters by changing the size of the effective pressure through microscopic observation. The percolation rate of coal rock based on microfracture, matrix, and coupling was studied by Shi et al. [12-23]. Yan et al. [24] established the effective pressure model of the porous medium by computer based on fractal technique to observe the change of the pore structure, thereby obtaining the fractal form of effective pressure. Yin et al. $[25,26]$ investigated the low of effective pressure on the percolation rate by loading and unloading associated with a developed experimental device. Xue et al. [27-31] expounded the influence of the effective pressure on the percolation rate of different rank coal through a series of stress sensitivity experiments. Gu et al. [32] carried out a series of experiments to study the briquette using the selfdeveloped experimental equipment and found out that the gas percolation rate varied significantly when the test pieces adsorbed different gases under the effective pressure. The potential links between the effective pressure and seepage field were proposed by Biot [33]. The seepage characteristics of limestone under different confining pressures and pore water pressures were studied by Siavash [34, 35], and the percolation rate equation based on effective pressure was put forward.

As far as the current research studies, many studies have focused on the effect of effective pressure changes under different conditions on the percolation rate of coal rock, and some achievements have been made in this field; however, the factors considered in the studies are still insufficient. Both coal mass deformation and gas stream during coal mining are affected by gas pressure, effective pressure, and temperature. It is known as the effect of thermo-solid gas coupling. The continuous change of the stress field in coal is partly due to the influence of the gas pressure field and temperature field. Therefore, when we study the influence of the effective pressure on the coal percolation rate, we must also take into account seriously the influence of temperature environment and gas pressure.

In this article, from the above perspective, the effective stress-based calculation formula for the percolation rate was proposed based on the study of the percolation rate characteristics of coal under different effective pressure conditions. In the meantime, the influence of temperature, gas pressure, and other factors was taken into account. In addition, the influence of effective pressure on the percolation rate of the coal body was studied using the thermosetting gas-coupling triaxial servo experiment equipment developed independently, and the obtained results are of theoretical and practical importance for the prevention and control of gas dynamic disasters.

\section{Percolation Rate Model Based on Effective Pressure}

In the case that the effective pressure acts on the raw coal, the effective pressure calculation formula is as follows:

$$
\sigma_{i j}^{\prime}=\sigma_{i j}-\alpha p \delta_{i j}
$$

where $\sigma_{i j}^{\prime}$ refers to the effective pressure $(\mathrm{MPa}), \sigma_{i j}$ represents the total stress ( $\mathrm{MPa}), \alpha$ denotes Biot's effective pressure coefficient, $P$ is the porous gas pressure $(\mathrm{MPa})$, and $\delta_{i j}$ refers to the symbol of Kronecker.

The potential links between the effective pressure coefficient and bulk modulus were proposed by Gesstsma and Skempton based on the experiment of porous rock in 1957, expressed as follows:

$$
\alpha=1-\frac{K}{K_{s}},
$$

where $K$ refers to the bulk modulus of coal $(\mathrm{MPa})$ and $K_{s}$ represents the bulk modulus of the coal skeleton $(\mathrm{MPa})$.

The adsorption of gas in coal is an isothermal process, which also follows the Langmuir equation. Coal is the dual medium of pore and fracture, and there are two kinds of competitions between gas and coal, that is, gas adsorption and gas mechanics. Gas adsorption leads to the expansion of the coal matrix, while gas mechanics results in the shrinkage of the coal matrix. When the raw coal is disturbed, the volume stress of coal redistributes, and the porosity also changes, which makes the percolation rate of coal change, and the effective pressure coefficient changes constantly. Considering the impact brought by the dual role of gas adsorption and gas dynamics, the expression of the bulk modulus $\left(K_{\mathrm{s}}\right)$ in equation (2) is expressed as follows:

$$
K_{s}=\frac{E_{s}}{3\left(1-2 v_{s}\right)} \frac{1}{[1-(\rho R T a \ln (1+b p) / p(1-\varphi))]},
$$

where $E_{s}$ refers to the elastic modulus of the coal skeleton $(\mathrm{MPa}), v_{s}$ represents Poisson's ratio of the coal skeleton, $a$ denotes the limit adsorption capacity of the coal sample under a certain pore pressure $\left(\mathrm{m}^{3} / t\right), b$ is the adsorption equilibrium constant of coal $\left(\mathrm{MPa}^{-1}\right), R$ refers to the molar gas constant, $R=8.3143 \mathrm{~J} /(\mathrm{mol} \cdot \mathrm{K}), \rho$ represents the density of coal $\left(\mathrm{kg} / \mathrm{m}^{3}\right), p$ denotes the porosity of the coal sample, and $T$ is the temperature of coal $\left({ }^{\circ} \mathrm{C}\right)$.

The change of porosity of the coal sample is related to the volume change of the structure of the coal. And, the expression of gap fraction is as follows:

$$
\varphi=\frac{\varphi_{0}+\varepsilon_{v}}{1+\varepsilon_{v}}
$$

Where $\varphi_{0}$ refers to the original gap fraction of coal, and $\varepsilon_{v}$ represents the volume deformation of coal. Considering the double action of gas adsorption and gas mechanics, the volume strain expression of coal is as follows:

$$
\varepsilon_{v}=-\frac{1}{K}(\bar{\sigma}-\alpha p)+\varepsilon_{s},
$$


where $\bar{\sigma}=\sigma_{i j} / 3$ and $\varepsilon_{s}$ refers to the volumetric strain induced by gas adsorption, and it can be expressed in the form similar to that of the Langmuir equation:

$$
\varepsilon_{s}=\varepsilon_{L} \frac{p}{p_{L}+p},
$$

where $\varepsilon_{L}$ refers to the maximum strain of coal when pore pressure is infinite and $p_{L}$ represents the pore gas pressure at half of the maximum volumetric strain of coal (MPa).

Substituting equation (3) into equation (2), the expression of the effective pressure coefficient is as follows:

$$
\alpha=1-\frac{3 K\left(1-2 v_{s}\right)}{E_{s}}\left[1-\frac{\rho R T a \ln (1+b p)}{p(1-\varphi)}\right] .
$$

The expression of effective pressure of coal is

$$
\Theta^{\prime}=\Theta-3 p\left\{1-\frac{3 K\left(1-2 v_{s}\right)}{E_{s}}\left[1-\frac{\rho R T a \ln (1+b p)}{p(1-\varphi)}\right]\right\},
$$

where $\Theta^{\prime}$ refers to the effective volume stress of coal (MPa) and $\Theta$ represents the volumetric stress of coal, $\Theta=\sigma_{1}+\sigma_{2}+\sigma_{3},(\mathrm{MPa})$.

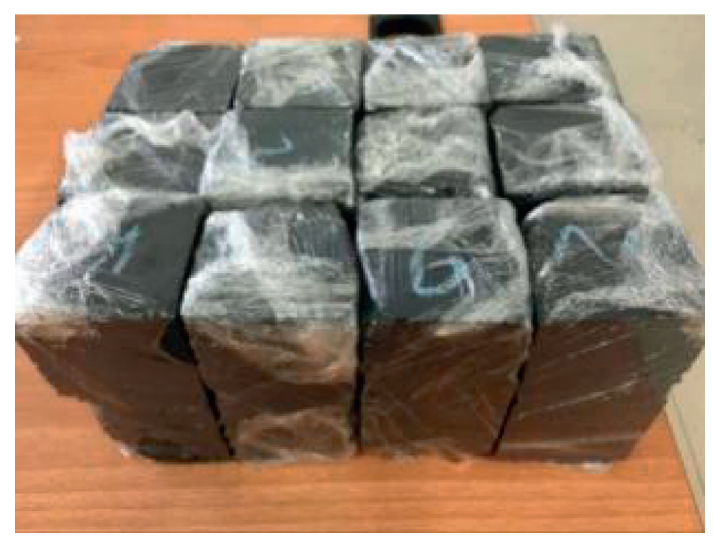

Figure 1: Specimens of raw coal.

The expression of percolation rate $K$ and effective pressure is as follows:

$$
k=c k_{0} \exp \left(d \Theta^{\prime}\right)
$$

where $k_{0}$ refers to the initial percolation rate of coal $\left(\mathrm{m}^{2}\right)$ and $d$ represents a constant.

Substitute equation (9) into equation (10):

$$
k=c k_{0} \exp \left(d\left\{\Theta-3 p\left\{1-\frac{3 K\left(1-2 v_{s}\right)}{E_{s}}\left[1-\frac{\rho R T a \ln (1+b p)}{p(1-\varphi)}\right]\right\}\right\}\right)
$$

where $c$ refers to a constant.

\section{Experiments and Methods}

3.1. Collection and Process of Coal. The test specimen was taken from Dong Hai Coal Mine, and complex weak structures were distributed in the coal. Reasonable raw coal samples were selected from the mine shaft, transported back to the laboratory for the production of standard raw coal specimens with a size of $50 \mathrm{~mm}^{*} 50 \mathrm{~mm}^{*} 100 \mathrm{~mm}$ by means of cutting and grinding, and then stored in a drying oven for later use. The coal body was dried to restore it to the original humidity roughly. At last, the samples were wrapped with the plastic wrap to avoid the occurrence of weathering. Raw coal is shown in Figure 1.

\subsection{Determination of Basic Physical Parameters of Coal.} Based on GBT 23561.3-2009 methods for the determination of physical and biomechanics character of coal and rock-Part 3: determination of bulk density of coal and rock; Part 4: calculation of porosity of coal and rock; Part 7: determination of single-axis compressive strength and softening coefficient to measure the density and initial porosity-some physical parameters of raw coal samples were obtained in the experiment. See Table 1 for details.

3.3. Laboratory Equipment. The core of this experiment equipment lies in the hot gas-solid-coupling three-axis servo experiment device. And, the experimental device is jointly developed by the unit in the place of our researchers and the instrument manufacturing company, which can simulate the stress field and temperature field under different parameters, as well as the seepage characteristics of gas pressure for the coal research experiment. It consists of six systems, i.e., pressure supply system, loading system, temperature regulating system, traffic monitoring system, stress and strain sensing system, and data acquisition and operating system. The theory of the experimental equipment and the actual diagram are displayed in Figure 2.

3.4. Testing Program. To study the influence of the effective pressure on the percolation rate of coal, this experiment adopted pure methane gas. Specifically, put the prepared sample into the true triaxial gripper, and install the loading indenters and sensor and gas loading line. Check the air tightness of each connection point of the equipment to prevent air leakage. Then, open the inflating valve, and continue to inflate for $1 \mathrm{~h}$, thus putting the specimen and pipe in a saturated gas state. First of all, the test is to adjust the pressure of the sealed osmotic water (confining pressure) to ensure the good air tightness of the equipment and the uniform loading of the specimen. The coal seepage test was carried out with the gas pressure of $0.3 \mathrm{MPa}, 0.9 \mathrm{MPa}$, and $1.5 \mathrm{MPa}$, respectively; the temperature are $30^{\circ} \mathrm{C}, 40^{\circ} \mathrm{C}, 50^{\circ} \mathrm{C}$, $60^{\circ} \mathrm{C}$, and $70^{\circ} \mathrm{C}$; and, the effective pressure are $2 \mathrm{MPa}, 4 \mathrm{MPa}$, $6 \mathrm{MPa}, 8 \mathrm{MPa}$, and $10 \mathrm{MPa}$, respectively. 
TABLE 1: Basic physical properties of experimental coal samples.

\begin{tabular}{lcccc}
\hline Elastic modulus $(\mathrm{MPa})$ & Poisson's ratio & Density $\left(\mathrm{kg} / \mathrm{m}^{3}\right)$ & Initial porosity & Initial percolation rate $\left(\mathrm{m}^{2}\right)$ \\
\hline 4100 & 0.23 & 1350 & 0.0828 & $7.8^{*} 10^{-15}$ \\
\hline
\end{tabular}

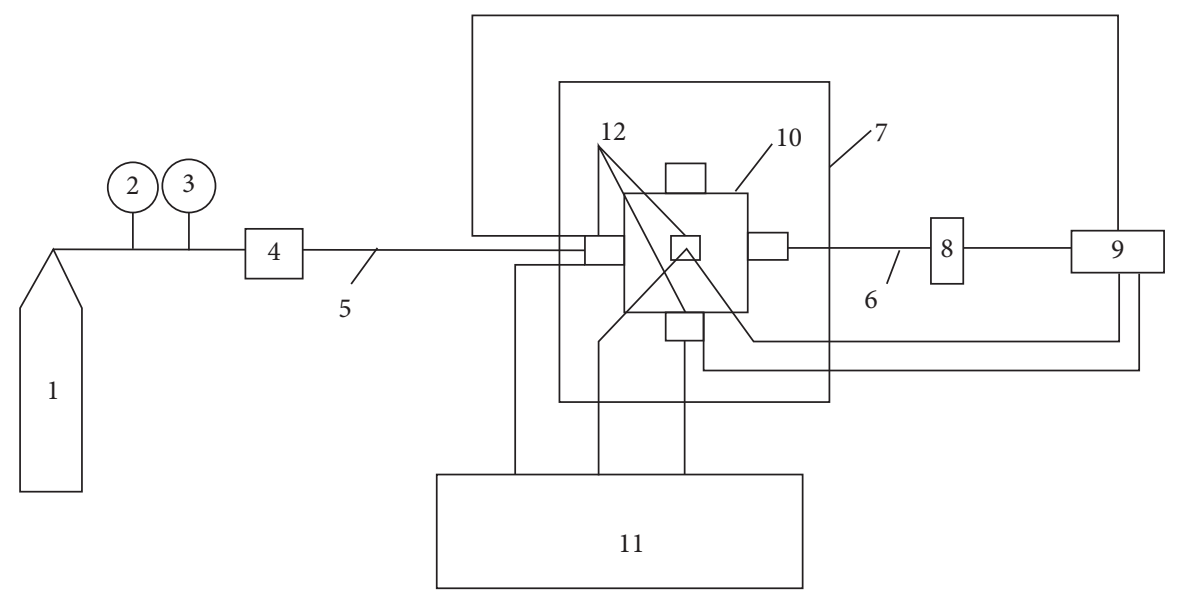

(a)

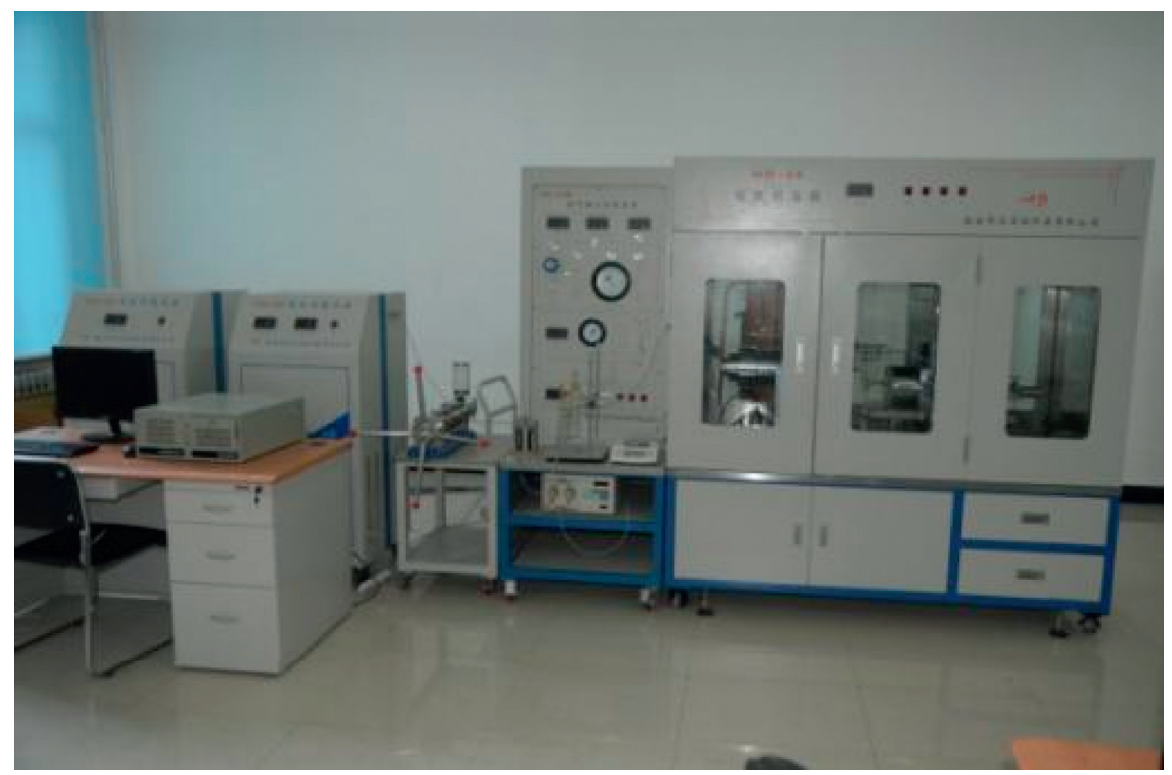

(b)

Figure 2: Thermos-solid-gas coupling equipment testing program. (a) Principle structure chart of the device. (1) Voltage gas supply source; (2) manometer; (3) pressure control valve; (4) pressure supply system; (5) intake gassing pipeline; (6) out gassing pipeline; (7) constanttemperature test chamber; (8) flow surveillance system; (9) data acquisition and operating system; (10) true triaxial fixture; (11) servo pump; (12) stress-strain and temperature sensor. (b) Experimental device.

3.5. Paper Analyses of Test Results. Based on the research status at home and abroad, it is known that coal is a method mediator with a complex structure, and there are massive pore throats in it; besides, their number, size, and connectivity play a decisive role in its percolation rate. The percolation rate $(K)$ can be calculated using the following formulation:

$$
K=\frac{2 Q p_{0} \mu L}{A\left(p_{1}^{2}-p_{2}^{2}\right)}
$$

where $K$ refers to the percolation rate $\left(\mathrm{m}^{2}\right), Q$ represents the permeation exhaust of gas in the experimental samples $(\mathrm{mL} / \mathrm{s}), p_{0}$ denotes the barometric pressure for the surveying spot, which is selected as the criterion barometric pressure of $0.101325 \mathrm{MPa}, \mu$ refers to the viscidity coefficient of the gas (MPa.s), $L$ represents the length of the experimental samples $(\mathrm{mm}), A$ denotes the cross-plane area of the experimental samples $\left(\mathrm{mm}^{2}\right)$, and $P_{1}$ and $P_{2}$ are the gas pressure of the air intake port and the outtake port air outlet (MPa), respectively. 


\section{Test Result Analysis}

To study the influence of effective pressure on the percolation rate of coal, the coal seepage test was carried out with gas pressures of $0.3 \mathrm{MPa}, 0.9 \mathrm{MPa}$, and $1.5 \mathrm{MPa}$, respectively; the temperatures are $30^{\circ} \mathrm{C}, 40^{\circ} \mathrm{C}, 50^{\circ} \mathrm{C}, 60^{\circ} \mathrm{C}$, and $70^{\circ} \mathrm{C}$, and the effective pressure are $2 \mathrm{MPa}, 4 \mathrm{MPa}, 6 \mathrm{MPa}, 8 \mathrm{MP}$, and $10 \mathrm{MPa}$, respectively. The experimental data can be seen in Tables 2-4. According to the test data, the relation curve between the coal body and the effective pressure is plotted under the combination of different temperatures and gas pressures, as shown in Figures 3-5.

The data was processed, and the correlation between the effective pressure and coal percolation rate is fitted as follows:

$$
\begin{aligned}
& y=7.10994 \exp (-0.08263 x)\left(R^{2}=0.99168\right) \\
& y=5.18943 \exp (-0.08558 x)\left(R^{2}=0.99428\right) \\
& y=4.10597 \exp (-0.08472 x)\left(R^{2}=0.99164\right) \\
& y=3.52293 \exp (-0.10544 x)\left(R^{2}=0.99945\right) \\
& y=2.85779 \exp (-0.10044 x)\left(R^{2}=0.99547\right)
\end{aligned}
$$

The data was processed, and the further fitting of the relationship between the two is as follows:

$$
\begin{aligned}
& y=2.08574 \exp (-0.08114 x)\left(R^{2}=0.99547\right) \\
& y=1.62320 \exp (-0.08414 x)\left(R^{2}=0.99385\right) \\
& y=1.27205 \exp (-0.08315 x)\left(R^{2}=0.99944\right) . \\
& y=1.02474 \exp (-0.09716 x)\left(R^{2}=0.99325\right) \\
& y=0.85006 \exp (-0.10052 x)\left(R^{2}=0.99737\right)
\end{aligned}
$$

The data was processed, and the further fitting of the relationship between the two is as follows:

$$
\begin{aligned}
& y=1.54815 \exp (-0.09609 x)\left(R^{2}=0.99844\right) \\
& y=1.14567 \exp (-0.09661 x)\left(R^{2}=0.99899\right) \\
& y=0.88532 \exp (-0.09248 x)\left(R^{2}=0.99749\right) . \\
& y=0.66233 \exp (-0.10215 x)\left(R^{2}=0.99976\right) \\
& y=0.54133 \exp (-0.10714 x)\left(R^{2}=0.99801\right)
\end{aligned}
$$

Based on Tables 2-5 and Figures 3-5, we can see that, in the experiment, the gas pressure and temperature were kept unchanged, and only the effective pressure was changed. Besides, the percolation rate of coal decreased gradually with the enhancement of effective pressure. When the effective pressure continued to increase, the weak structure of the coal body was continuously compacted, and the cross-section area of the pore throat continued to decrease, impeding the seepage and leading to the reduction of the percolation rate of the coal material. At the temperature of $30^{\circ} \mathrm{C}$, due to the low temperature, thermal effect on coal is small; therefore, the coal body was mainly influenced by the valid pressure,
TABLE 2: The percolation rate of coal under different effective pressure at the pressure of $0.3 \mathrm{MPa}$.

\begin{tabular}{lccccc}
\hline \multirow{2}{*}{ Effective pressure (MPa) } & \multicolumn{5}{c}{$\mathrm{T}\left({ }^{\circ} \mathrm{C}\right)$} \\
& 30 & 40 & 50 & 60 & 70 \\
\hline 2 & 5.98 & 4.34 & 3.52 & 2.86 & 2.35 \\
4 & 5.17 & 3.69 & 2.84 & 2.31 & 1.88 \\
6 & 4.42 & 3.18 & 2.46 & 1.85 & 1.57 \\
8 & 3.71 & 2.64 & 2.11 & 1.52 & 1.32 \\
10 & 2.99 & 2.13 & 1.78 & 1.24 & 1.02 \\
\hline
\end{tabular}

TABle 3: The percolation rate of coal under different effective pressure at the pressure of $0.9 \mathrm{MPa}$.

\begin{tabular}{lccccc}
\hline \multirow{2}{*}{ Effective pressure (MPa) } & \multicolumn{5}{c}{$\mathrm{T}\left({ }^{\circ} \mathrm{C}\right)$} \\
& 30 & 40 & 50 & 60 & 70 \\
\hline 2 & 1.80 & 1.39 & 1.08 & 0.84 & 0.69 \\
4 & 1.48 & 1.13 & 0.91 & 0.71 & 0.58 \\
6 & 1.28 & 1.01 & 0.77 & 0.56 & 0.46 \\
8 & 1.10 & 0.83 & 0.65 & 0.46 & 0.38 \\
10 & 0.93 & 0.71 & 0.56 & 0.40 & 0.31 \\
\hline
\end{tabular}

TABle 4: The percolation rate of coal under different effective pressure at the pressure of $1.5 \mathrm{MPa}$.

\begin{tabular}{lccccc}
\hline \multirow{2}{*}{ Effective pressure (MPa) } & \multicolumn{5}{c}{$\mathrm{T}\left({ }^{\circ} \mathrm{C}\right)$} \\
& 30 & 40 & 50 & 60 & 70 \\
\hline 2 & 1.27 & 0.95 & 0.74 & 0.54 & 0.44 \\
4 & 1.06 & 0.77 & 0.61 & 0.44 & 0.35 \\
6 & 0.88 & 0.64 & 0.50 & 0.36 & 0.28 \\
8 & 0.72 & 0.53 & 0.42 & 0.29 & 0.23 \\
10 & 0.58 & 0.44 & 0.36 & 0.24 & 0.19 \\
\hline
\end{tabular}

TABLE 5: The material parameters of the model.

\begin{tabular}{lc}
\hline Parameter name & Numerical value \\
\hline Modulus of elasticity & $6.78^{*} 10^{8} \mathrm{MPa}$ \\
Poisson's ratio & 0.35 \\
Original porosity & 0.0828 \\
Initial percolation rate & $8.0^{*} 10^{-15} \mathrm{~m}^{2}$ \\
Gas density & $0.714 \mathrm{~kg} / \mathrm{m}^{3}$ \\
Gas dynamic viscosity coefficient & $1.08^{*} 10^{-5} \mathrm{~Pa} \cdot \mathrm{s}$ \\
Thermal conductivity & $0.443 \mathrm{~J} /(\mathrm{m} \cdot \mathrm{s} \cdot \mathrm{K})$ \\
Specific heat & $4.35 \mathrm{~J} /(\mathrm{kg} \cdot \mathrm{K})$ \\
Coefficient of thermal expansion & $1.2^{*} 10^{-4} 1 / \mathrm{K}$ \\
Gas compression ratio & $4^{*} 10^{-10} 1 / \mathrm{Pa}$ \\
Gas specific heat & 1.4 \\
\hline
\end{tabular}

and the influence of temperature on the skeleton of the coal could be neglected; in this case, the percolation rate reduced quickly. With the increase of temperature, the thermal effect on coal body skeleton and gas adsorption was deepened, and the deformation caused by the temperature cannot be ignored. At high temperature, the percolation rate decreased gently.

Through the above research, it can be found that when the temperature and gas pressure are kept stable, the percolation rate of the coal specimen reduces with the increase 


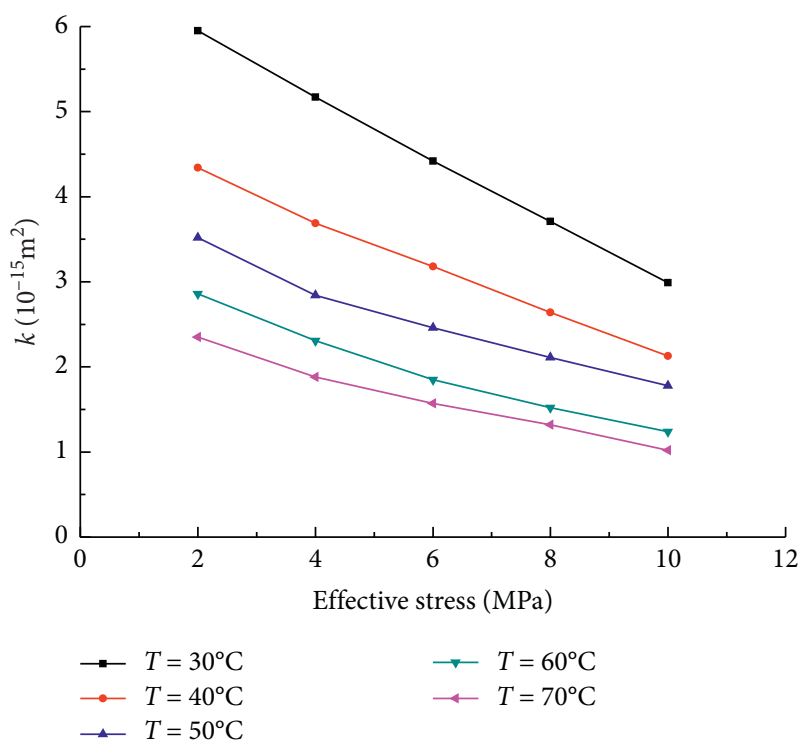

Figure 3: Percolation rate of coal with effective stress under different temperatures at the gas pressure of $0.3 \mathrm{MPa}$.

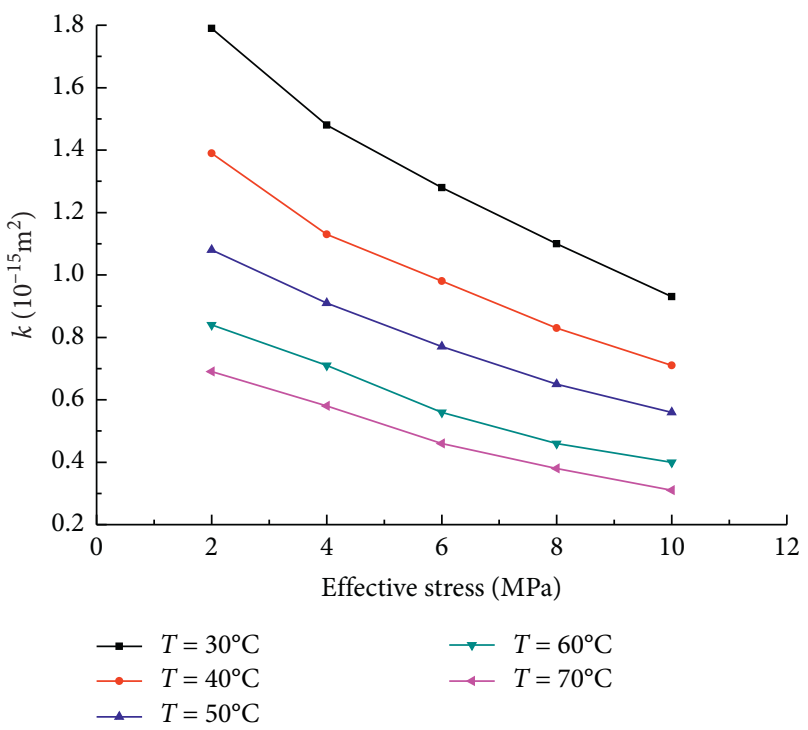

Figure 4: Percolation rate of coal with effective pressure under different temperatures at the gas pressure of $0.9 \mathrm{MPa}$.

of the effective pressure. The relational expression can be expressed by the following formula:

$$
k=a \cdot e^{b \sigma}
$$

where $K$ refers to the percolation rate, $\sigma$ represents the effective pressure, and $a$ and $b$ denote the fitting coefficient.

\section{Validation of Theoretical Equation of Effective Pressure and Percolation Rate}

On the basis of the above experimental research and analysis, a mathematical model was established for the correlation between effective pressure and percolation rate. In view of the complexity of the mathematical model, we used the numerical method to further solve it. The modeling steps are as follows. (1) Establish a realistic geometric model according to the relevant background. (2) Define the physical parameters of the model. The first step is to define the solution domain, that is, the theoretical relation of the effective pressure and the percolation rate of the coal body is input into COMSOL for calculation by using the partial differential equations PDE. The second step defines the physical parameters, such as elastic modulus, Poisson's ratio, density, and so on, which are measured by experiments. (3) The initial borderline requirement of the mock-up is set up 


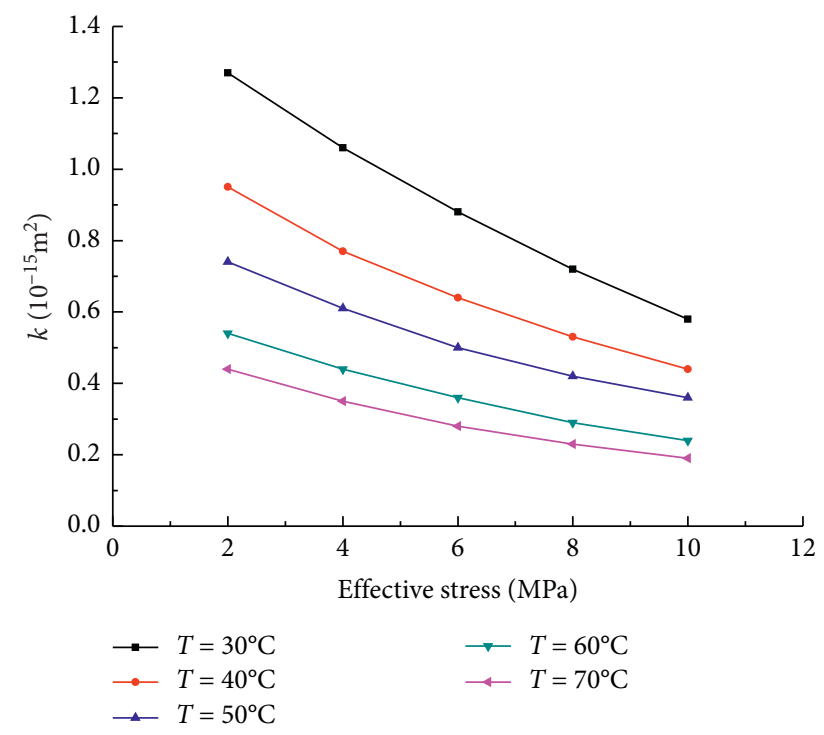

Figure 5: Percolation rate of coal with effective stress under different temperatures at the gas pressure of $1.5 \mathrm{MPa}$.

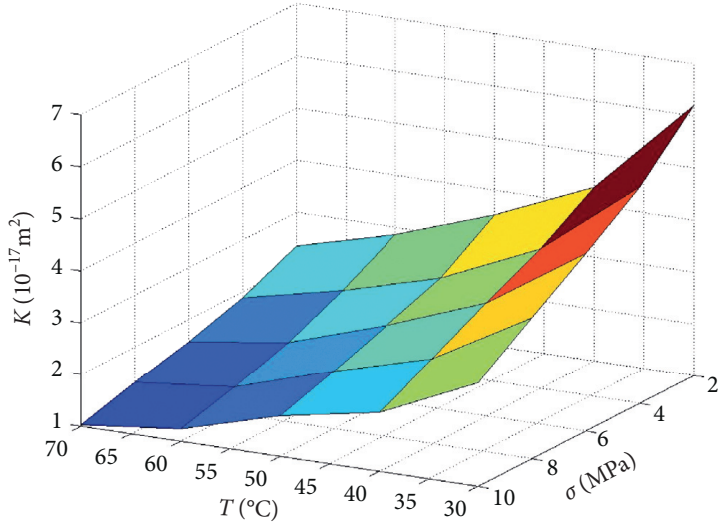

(A)

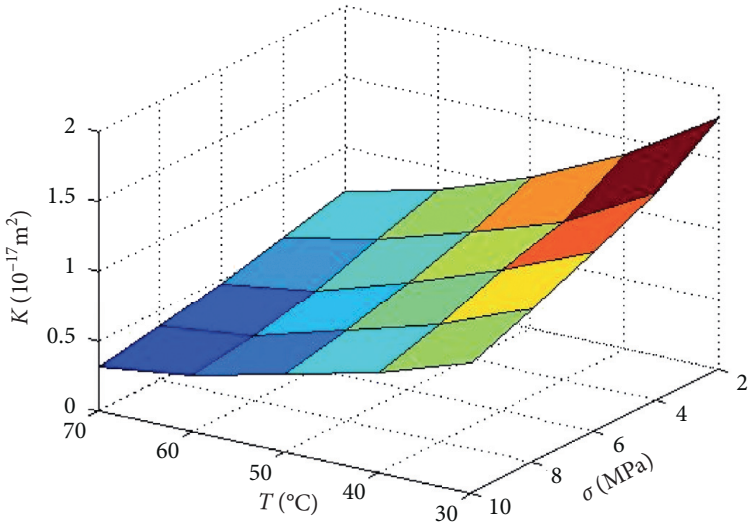

(B)

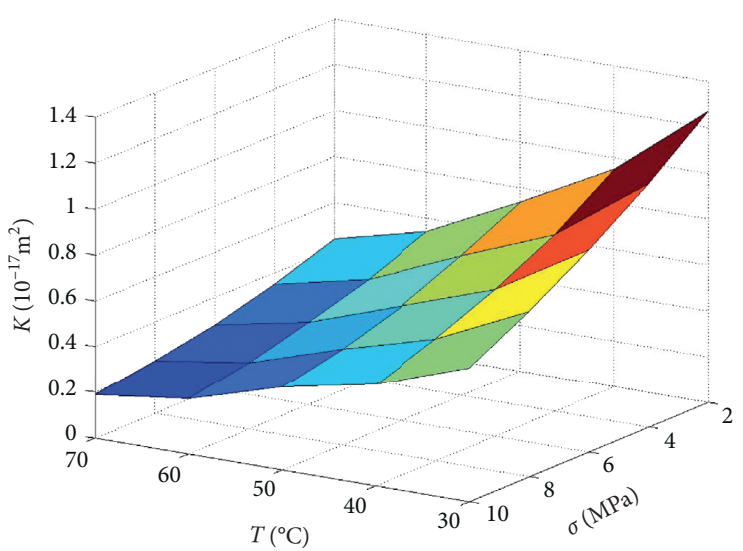

(C)

(a)

Figure 6: Continued. 


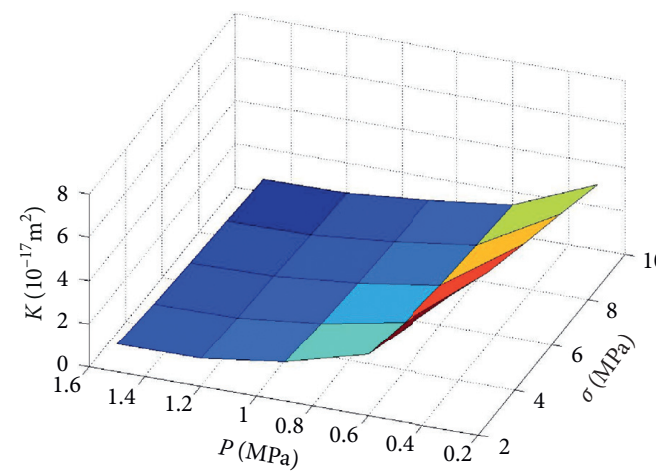

(A)

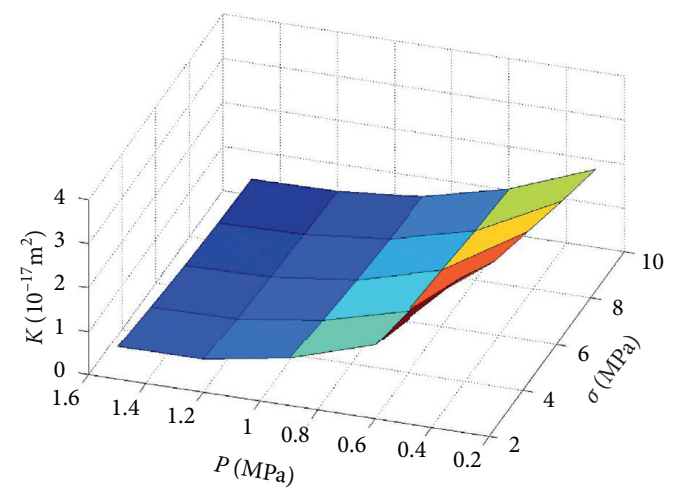

(B)

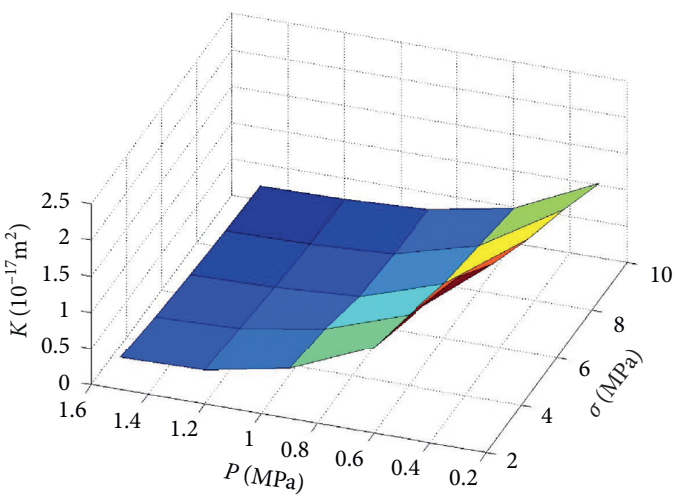

(C)

(b)

Figure 6: The percolation rate surface of coal. (a) k-T- $\sigma$ graphs of coal samples. (A) $p=0.3 \mathrm{MPa}$. (B) $p=0.6 \mathrm{MPa}$. (C) $p=0.9 \mathrm{MPa}$. (b) k- $p-\sigma$ graphs of coal samples. (A) $T=30^{\circ} \mathrm{C}$. (B) $T=50^{\circ} \mathrm{C}$. (C) $T=70^{\circ} \mathrm{C}$.

according to the concrete conditions. (4) Division of the element grid. (5) Solving calculation. (6) Visual postprocessing.

In this paper, a finite element model with the bottom bound by displacement was built according to the size of the raw coal standard sample at $1: 1$. The specific physical parameters are set in Table 5. From the perspective of the seepage experiment, the boundary conditions of the model were further refined. The gas pressure with an initial pressure of $p_{0}=0.1 \mathrm{MPa}$ and an initial temperature of $T$ was applied to the upper boundary, and the gas was allowed to flow freely in the coal under the condition of self-weight load and the effective pressure of $\sigma$.

According to the conditions obtained by changing the model of the gas pressure and temperature threshold, to simulate the environment featured by different effective pressure and study the percolation rate of the coal sample, the operation procedure to calculate the percolation rate of coal samples under the attribute values of different stress conditions was imported into the data analysis software of
Matlab, thereby further fitting out the connection between the percolation rate and effective pressure surface figure. And, the change rule of percolation rate and effective pressure is shown in Figure 6.

Under the hypothesis of ensuring the gas pressure, in the case that the effective pressure increases at certain temperature, the experiment shows that the percolation rate of coal changes obviously in the early stage, showing a rapid decline trend, and starts to change slowly when it reaches a certain value. As the effective pressure continues to increase, the weak structure of the coal body continuously compacted, and the cross-sectional area of the pore throat continues to decrease, which hinders the seepage, and leads to the decrease of the coal seepage rate. When the pressure reaches a certain strength, the compression deformation effect of coal decreases, and the change of seepage channel morphology tends to be stable. Hence, the change rate of the seepage rate coefficient decreases gradually and then stabilizes. The results of the theoretical calculation are in good agreement with the experimental results, which shows that the effective 
pressure and percolation rate equation of coal have good applicability, and can be used to investigate the change of the seepage velocity of coal under different effective pressures.

\section{Conclusion}

Through the construction of different effective pressure conditions, the following conclusions were made based on a large number of experimental verifications and theoretical research studies on the coal percolation rate.

(1) The theory and experiment of double means were used to further research the stress and the influence of temperature on the physical properties of coal, and starting from the basic definition of relevant parameters, the effect of mechanical parameters on coal gas was deduced, including the role of the relationship between temperature, percolation rate, and function equation. Then, the effective pressure and the relation between coal were concluded.

(2) The change of the percolation rate of coal under effective pressure was studied by changing the gas pressure and temperature using the self-developed triaxial servo-controlled seepage equipment for thermos-solid-gas coupling. The relationship between the effective pressure and percolation rate of coal was obtained, thereby fitting the relation expression and revealing the change law of effective pressure and percolation rate of coal. The results showed that when both the gas pressure and the temperature were kept constant, the effective pressure inhibited the percolation rate of the coal body, and the effective pressure increases in the opposite direction.

(3) The theoretical equation for effective pressure and percolation rate of coal was calculated through the finite element software COMSOL, thereby obtaining the effective pressure and percolation rate of the coal surface. Besides, the obtained theoretical results were in good agreement with the experimental results, indicating that the effective pressure and percolation rate of the coal theory equation had good applicability. The research results showed certain guiding value for gas treatment methods and safety prevention in the process of coal mining.

\section{Data Availability}

The data used to support the findings of this study are included within the article.

\section{Conflicts of Interest}

The authors declare that they have no conflicts of interest.

\section{Acknowledgments}

The work was supported by the National Natural Science Foundation of China (51774121 and 52074110), and Innovative Scientific Research Project for Postgraduates of
Heilongjiang University of Science and Technology (YJSCX2020-103HKD).

\section{References}

[1] D. Jiang, G. Zhang, Y. Hu et al., "Study on the effect of effective pressure on the percolation rate of coal bed gas," Journal of Chongqing University, vol. 20, no. 5, pp. 22-25, 1997.

[2] J. Tang, Y. pan, C. Li, Z. Dong, and Q. Shi, "Experimental study on effect of effective pressure on desorption and seepage of coalbed methane," Chinese Journal of Rock Mechanics and Engineering, vol. 25, no. 3, pp. 1564-1567, 2006.

[3] H. Zhu, Study on Permeability Evolution Law of Coal Rock with Adsorbed Gas during Deformation process, Shandong University, Jinan, China, 2018.

[4] Y. He and L. Yang, "Study on the effect of temperature and effective pressure on percolation rate of sandstone," Chinese Journal of Rock Mechanics and Engineering, vol. 24, no. 14, pp. 2420-2426, 2005.

[5] G. Yao, M. Tang, P. Zheng, S. Duan, and H. Zhang, "Experimental study on the influence of pore pressure and temperature on nitrogen seepage in coal rock," Coal Mine Safety, vol. 52, no. 03, pp. 19-24, 2021.

[6] B. Li, B. Wang, Y. Kang, J. Li, C. Ren, and X. Jiang, "Penetration mechanism of coal rock under combined action of stress and temperature," Journal of China University of Mining and Technology, vol. 49, no. 05, pp. 844-855, 2020.

[7] P. Zeng, J. Zhao, Z. Li et al., "Experimental study on the effect of temperature, effective pressure and water saturation on percolation rate of low percolation rate sandstone," Natural Gas Geoscience, vol. 16, no. 1, pp. 31-34, 2005.

[8] P. Zeng and J. Li, "Coordinate transformation method for seepage calculation of heterogeneous dams," Chinese Journal Of Geotechnical Engineering, vol. 15, no. 04, pp. 59-65, 1993.

[9] P. Dai, L. T. sun, and M. Li, "Study on relation between porosity/percolation rate and effective pressure of sand reservoir with low percolation rate," Natural Gas Industry, vol. 26, no. 5, pp. 93-95, 2006.

[10] Y. Kang, H. Zhang, and L. Yu, "The application of nuclear magnetic resonance logging in gas-bearing tight sandstone," Natural Gas Industry, vol. 27, no. 3, pp. 46-48, 2007.

[11] Z. Zhao, W. Sun, S. Chen, D. Yin, H. Liu, and B. Chen, "Determination of critical criterion of tensile-shear failure in Brazilian disc based on theoretical analysis and meso-macro numerical simulation," Computers and Geotechnics, vol. 134, 2021.

[12] X. Shi, Structure Characteristics of Microfractures in Coal and its Control Mechanism on Coal Permeability, Henan Polytechnic University, Jiaozuo, China, 2018.

[13] B. Wang, B. Li, S. Xu et al., "Study on permeability characteristics of coal rock matrix-fracture interaction," Coal Science and Technology, 2021.

[14] L. Zhang, W. Huchao, D. Wang et al., "Experimental evaluation of coal rock fracture seepage capacity and equivalent permeability analysis of near wellbore formation," Science, Technology and Engineering, vol. 21, no. 02, pp. 495-503, 2021.

[15] H. Chuanbo, Z. Hou, F. Xiao, and G. Liu, "Experimental study on influence of borehole arrangement on energy conversion and acoustic characteristics of coal-like material sample," Shock and Vibration, vol. 2020, Article ID 4790587, 15 pages, 2020.

[16] Z. Hou, H. Chuanbo, F. Xiao, and G. Liu, "Research on energy conversion and damage features of unloading instability of 
sandstone under high stress," Advances in Civil Engineering, vol. 2021, Article ID 6655968, 15 pages, 2021.

[17] J. Li, Study on Coal Rock Deformation and Permeability Evolution under Gas-Water coupling, Guizhou University, Guiyang, China, 2020.

[18] C. Chen, Experimental Study on Seepage and Acoustic Emission Characteristics of Coal Rock under Thermal-Mechanical coupling, Taiyuan University of Technology, Taiyuan, China, 2019.

[19] Y. Zhao, Y. Wang, W. Wang, L. Tang, Q. Liu, and G. Cheng, "Modeling of rheological fracture behavior of rock cracks subjected to hydraulic pressure and far field stresses," Theoretical and Applied Fracture Mechanics, vol. 101, pp. 59-66, 2019.

[20] W. Mu, L. Li, T. Yang, G. Yu, and Y. Han, "Numerical investigation on grouting mechanism with slurry-rock coupling and shear displacement in single rough fracture," Bulletin of Engineering Geology and the Environment, vol. 78, no. 8, pp. 6159-6177, 2019.

[21] F. Xiao, J. He, Z. Liu, Z. Shen, and G. Liu, "Analysis on warning signs of damage of coal samples with different water contents and relevant damage evolution based on acoustic emission and infrared characterization," Infrared Physics and Technology, vol. 97, pp. 287-299, 2019.

[22] F. Xiao, X. Meng, L. Li et al., "Thermos-solid-gas coupling dynamic model and numerical simulation of coal containing gas," Geofluids, vol. 2020, Article ID 8837425, 9 pages, 2020.

[23] H. Xianjie, W. Du, Y. Zhao et al., "Dynamic tensile behaviour and crack propagation of coal under coupled static-dynamic loading," International Journal of Mining Science and Technology, vol. 30, pp. 2095-2686, 2020.

[24] T. Yan, W. Li, and X. Bi, "Based on fractal method of porous media effective pressure model," Rock and Soil Mechanics, vol. 31, no. 8, pp. 2625-2629, 2010.

[25] G. Yin, W. Li, M. Li et al., "Percolation rate properties and effective pressure of raw caol under loading-unloading condition," Journal of China Coal Society, vol. 39, no. 8, pp. 1497-1503, 2014.

[26] W. Aidong, Study on Mechanical and Permeability Characteristics of Raw Coal under Loading and Unloading Stress, Chongqing University, Chongqing, China, 2019.

[27] X. Pei, P. Zheng, and J. Wen, "Influence of effective pressure on percolation rate of different rank coals," Science and Technology Review, vol. 33, no. 2, pp. 69-73, 2015.

[28] G. Jiang, Study on Damage Evolution Law and Permeability Characteristics of Coal Rock under Fluid-Solid Coupling, Shandong University of Science and Technology, Qingdao, China, 2018.

[29] J. Guo, Experimental Study on Permeability Evolution of Coal Samples under Plastic flow, China University of Mining and Technology, Xuzhou, China, 2018.

[30] Y. Xue, Study on Permeability Evolution Law of Fractured Coal and Rock Mass under Mining influence, China University of Mining and Technology, Xuzhou, China, 2017.

[31] Y. Zou and B. Cheng, "Experimental study on the mapping law of coal-rock loading process and gas permeability characteristics," Coal Science and Technology, vol. 47, no. 11, pp. 224-230, 2019.

[32] D. Gu, X. Xian, and J. Zhou, "Experiment study of the influence of effective pressure and different gases on coal percolation rate," Journal of Underground Space and Engineering, vol. 8, no. 6, pp. 1296-1301, 2012.
[33] M. A. Biot, "Chinese Journal of underground space and engineering," Journal of Applied Physics, vol. 12, no. 2, pp. 155-164, 1941.

[34] G. Siavash, S. Jean, G. Sylvine et al., "Effective pressure law for the percolation rate of a limestone," International Journal of Rock Mechanics \& Mining Sciences, vol. 46, no. 2, pp. 297-306, 2009.

[35] X. Liu, Experimental Study on Water Seepage under High Confining Pressure in Filled Fractured rock, Central South University, Changsha, China, 2012. 